\title{
Spousal Burden and Coping across Patient Groups of Three Serious Mental Illnesses- A Comparative Study
}

\author{
Jayamadhuri Mothukuri ${ }^{1}$, Ashok Reddy Karredla² \\ ${ }^{1}$ Department of Psychiatry, Shadan Institute of Medical Sciences, Moinabad, Hyderabad, Telangana, India. \\ ${ }^{2}$ Department of Psychiatry, SVS Medical College, Mahbubnagar, Telangana, India.
}

\section{ABSTRACT}

\section{BACKGROUND}

Serious psychiatric conditions like schizophrenia, bipolar disorder, alcohol dependence syndrome lead to a great burden in care givers who adopt a variety of styles to cope with their family member's illness. Burden perceived and coping styles used by spouses is quite different from other care givers given their close relationship with the patient. Little research is focused on spouses as an exclusive group for their assessment of burden \& coping. The aim was to compare the burden and coping in spouses across three patient groups with schizophrenia, bipolar disorder and alcohol dependence syndrome.

\section{METHODS}

This was conducted at Institute of Mental Health, Hyderabad with 180 spouses (30 male \& 30 female) from patients of above three illnesses. After IEC approval and a written informed consent, the patient and spouse were interviewed with the semistructured intake pro-forma to capture socio-demographic details of spouse, illness, marital, family \& treatment history. After initial assessment of patient's functional status using GAF scale; BAS, CCL, GHQ-12 instruments were administered on spouses to assess the burden of illness, coping styles and general health status. Data was analysed with SPSS 17.

\section{RESULTS}

Alcohol use and mental illness is high in families of patients with alcohol dependence reaching statistical significance. Nuclear families are high in schizophrenia group and in alcohol dependence group, substance use in spouses is high at $25(52.1 \%)$ along with abuse of spouses at $19(67.9 \%)$ which is statistically significant. On ANOVA \& post hoc analysis, means of GHQ-12 in alcohol dependence group is higher than other groups while means of BAS is higher in alcohol dependence group showing high scores on BAS factor analysis.

\section{CONCLUSIONS}

Burden perceived by spouses of these three patient groups is significant. The coping styles used by spouses to handle the distress due to patient's illness are many. A high global functioning score of the patient corresponds to good general health in the spouse. Proper psychosocial interventions when employed can help spouses deal better with burden and enhance coping styles.

\section{KEY WORDS}

Spouses, Burden, Coping, General Health, Schizophrenia, Bipolar Disorder, Alcohol Dependence Syndrome
Corresponding Author: Dr. Jayamadhuri Mothukuri, H. No. 11-24-108, Shathavahanapuri, Desaipet Road, Warangal-506002, Telangana, India.

E-mail:jmothukure@gmail.com

DOI: 10.14260/jemds/2020/295

Financial or Other Competing Interests: None.

How to Cite This Article:

Mothukuri J, Karredla AR. Spousal burden and coping across patient groups of three serious mental illnesses- a comparative study. J. Evolution Med. Dent. Sci. 2020;9 (16):1354-1358, DOI: 10.14260/jemds/2020/295

Submission 24-03-2019, Peer Review 29-03-2020, Acceptance 06-04-2020, Published 20-04-2020.

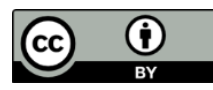




\section{BACKGROUND}

Severe mental morbidity causes long duration illness hampering the expected societal roles of patients for their age and ability. Deinstitutionalization has resulted in care of the mentally ill by their families within the community. ${ }^{1}$ Burden and coping are two of the forms used to evaluate mental illness impact on caregivers. Serious psychiatric conditions like schizophrenia, bipolar disorder, alcohol dependence syndrome lead to great burden in care givers who adopt a variety of styles to cope with their family member's illness. Burden perceived and coping styles used by spouses is quite different from other care givers given their close relationship with the patient. The subjective component of burden has also been found to be highly prevalent, with 29 to $60 \%$ of the caregivers suffering from diagnosable psychiatric disorders. ${ }^{2}$ Research evidence on family caregivers of persons with Schizophrenia found their inability to cope with a considerable amount of the caring roles and responsibilities due to inadequate help and support. $^{3}$ The occurrence of mental illness in a family member usually results in psychological and emotional disturbances of the whole family. 4

The stigma associated with a relative's mental illness causes impact which by family caregivers should cope. ${ }^{5}$ Schizophrenia has more effect on family burden than the financial burden. Family burden in other psychiatric disorders e.g. bipolar disorder, obsessive compulsive disorder; substance dependence disorder is also comparable to Schizophrenia. One study highlighted that the family burden and financial burden were significantly higher in persons with Schizophrenia when compared with other mental disorders. ${ }^{6}$ The severity of family burden in families of Schizophrenia patients has no difference from that of relatives of Bipolar disorder.7,8 Data suggests that in Bipolar disorder, higher degree of family burden leads to worse psychosocial functioning of patients. Also, depressive episodes found to trigger substantially higher severity of family burden than manic episodes. The main determinants of significant level of family burden are found to be an occurrence of depression during the previous two years, and a diagnosis of rapid cycling. During remission also high level of family burden sustained which seems to be driven by fear of illness recurrences, social withdrawal, and patient's social impairment. ${ }^{9}$

Long years of heavy alcohol use contribute to chronic diseases and traumatic outcomes that kill or disable at relatively young age, resulting in the loss of productive years. Burden caused by disruptive activities of the substance dependent person, and financial difficulties due to loss of income and/or diversion of funds to substance dependence lead to psy-chological problems in spouses. Coping adapted by caregivers are problem-focused or emotion- focused strategies while the consistent correlates of coping are caregiver-burden, patient's social functioning, expressed emotions of caregivers and available social support. High levels of burden, dysfunction, and expressed emotions together with low levels of available support have been associated with maladaptive emotion-focused styles.
Positive care giving experience is found to be related to use of problem-focused coping and seeking of social support. A study explored that problem focused coping strategies were more frequent among young relatives and relatives of younger patients. Relatives who had been living longer with the patient and had poor social support more frequently adopted emotion-focused strategies. ${ }^{10}$ The coping behaviour of wives of alcohol dependent persons is emotional, tolerant, inactive, controlling, confronting and supporting the user. Although caregivers of patients with Schizophrenia used some of the emotion-focused strategies more often, the coping patterns of caregivers of Schizophrenia and Bipolar disorder are quite alike. ${ }^{11}$

On examining burden in parents and spouses of persons with Schizophrenia, greater emotional burden was reported in the latter. Also, denial as a coping strategy was used by parents, while spouses used more of negative distraction strategies. Patient's age, educational level, level of functioning and caregiver's use of denial as a coping strategy predicted the caregiver burden. ${ }^{12,13}$ Burden of Schizophrenia in caregivers when reviewed found that relatives of male patients frequently experience more social dysfunction and disabilities than those of female patients. ${ }^{14}$ Among relatives of patients with Bipolar affective disorder, greater than $90 \%$ reported severe subjective and objective burden at admission while at follow up, none of the family members reported severe subjective burden but severe objective burden was seen in a quarter of them. In conclusion, severe burden was experienced initially by almost all caregivers and after symptoms subsided, they experienced financial burden specifically. ${ }^{15}$

The study of costs and consequences of caring for a relative or friend with Bipolar disorder found more physical health problems, depressive symptoms, health risk behaviour, health service use and less social support in high burden caregivers than less burden caregivers. The conclusion of the study is burden experienced are associated with problems in health, mental health, and cost.16,17 The pattern of burden when assessed in caregivers of men with alcohol and opioid dependence showed more often the alcohol dependence group was older, married, currently working with a higher income and the wife as a caregiver. Almost all (95-100\%) caregivers reported a moderate or severe burden indicating the gravity of the situation and the need for further work-up. ${ }^{18}$ Female spouses of male at-risk drinkers confirmed high level of psychological distress which was measured with scales that measures anxiety, depression, aggressivity and cognitive impairments. ${ }^{19}$ Coping and its correlates when examined revealed caregivers of bipolar patients used problem-focused strategies while emotion-focused strategies were used by caregivers of schizophrenic patients which appears to be linked to differences in caregiver-burden and appraisal between the two groups. ${ }^{20}$

Experience of care giving when studied in a group of caregivers of Bipolar patients in comparison with Schizophrenia, the maximum Experience of Care giving Inventory (ECI) score was seen in the domain of handling 'difficult behaviour' in both the groups. However, Schizophrenia group had overall more positive and negative appraisal of 
care giving experience while caring for their ill relatives. There were significant differences too for the total positive personal experience sub-score. ${ }^{21} \mathrm{~A}$ comparison of caregivercoping in BPAD and Schizophrenia revealed high levels of patient-dysfunction and caregiver-burden, low awareness of illness and low perceived control over patient's behaviour in both BPAD and Schizophrenia, with no significant differences between the two groups. Coping patterns were also quite alike, though Schizophrenia group used some emotion-focused strategies significantly more often. ${ }^{9}$ Studies on spouses as an exclusive caregiver group are needed to compare the amount of perceived burden and coping styles in them.

The aim was to compare the burden and coping across spouses of patients with schizophrenia, bipolar disorder and alcohol dependence syndrome.

\section{METHODS}

This comparative study was conducted at Institute of Mental Health, Hyderabad after receiving IEC clearance with 180 subjects. Sample size was taken based on the convenience of the study. 60 each are Spouses of patients with diagnosis of schizophrenia, bipolar affective disorder and alcohol dependence as per ICD-10, and age between 18 to 60 years, both genders ( 30 male \& 30 female), primary caregiver for more than 2 years were included with no history of cognitive impairment, mental retardation, other psychiatric illnesses. After a written informed consent from the patient and spouse, they were interviewed with the semi-structured intake pro-forma to capture the socio-demographic data and details of spouse, illness, marital history, family history \& treatment history. Initially, functional status of patient was assessed using Global assessment of functioning (GAF) scale. Subsequently, Burden assessment schedule (BAS), ${ }^{22}$ Coping checklist (CCL), ${ }^{23}$ General health questionnaire (GHQ-12) was administered on spouses to assess the burden of illness, coping styles and general health status.

\section{Statistical Analysis}

The data collected was subjected to analysis using SPSS 17 version with Chi-square test, one- way ANOVA, post hoc analysis (LSD).

\section{RESULTS}

\begin{tabular}{|ccccc|}
\hline Variable & Male & Female & $\begin{array}{c}\text { T test } \\
\text { (F value) }\end{array}$ & $\begin{array}{c}\text { SIG (2 } \\
\text { Tailed) }\end{array}$ \\
GHQ-12 & $18.66(2.31)$ & $18.69(3.09)$ & 1.009 & 0.935 \\
BAS & $81.8(6.1)$ & $81.3(5.6)$ & 0.634 & 0.614 \\
CCL-Problem Solving & $1.47(0.69)$ & $1.28(0.54)$ & 10.07 & $0.043^{*}$ \\
CCL-Social Support & $1.84(1.05)$ & $1.55(0.91)$ & 0.139 & $0.05^{*}$ \\
\hline Table 1. Comparison of GHQ-12, BAS and Coping Subscales \\
across Gender of the Spouse \\
\hline
\end{tabular}

Table 1 shows the mean score of General health questionnaire and standard deviation across male and female groups is 18.66 (2.31), 18.69 (3.09) respectively with $\mathrm{F}$ value of $1.009 \& \mathrm{p}$-value 0.935 which is not statistically significant. The mean score of Burden assessment schedule between the two gender groups is 81.8 (6.1) and 81.3 (5.6), which is not statistically significant.

\begin{tabular}{|c|c|c|c|c|c|c|}
\hline & & Post HOC A & nalysis & & & \\
\hline (I) & (J) & Mean & Std. & & $\begin{array}{r}95 \% \text { Co } \\
\text { Inte }\end{array}$ & $\begin{array}{l}\text { fidence } \\
\text { val }\end{array}$ \\
\hline $\begin{array}{l}\text { Diagnosis } \\
\text { of Patient }\end{array}$ & $\begin{array}{l}\text { Diagnosis } \\
\text { of Patient }\end{array}$ & $\begin{array}{l}\text { Difrerence } \\
\text { (I-J) }\end{array}$ & Error & Sig. & $\begin{array}{l}\text { Lower } \\
\text { Bound }\end{array}$ & $\begin{array}{l}\text { Upper } \\
\text { Bound }\end{array}$ \\
\hline & Schizophrenia & .583 & .489 & .234 & -.38 & 1.55 \\
\hline BPAD & $\begin{array}{c}\text { Alcohol } \\
\text { dependence }\end{array}$ & -.850 & .489 & .084 & -1.81 & .11 \\
\hline & BPAD & -.583 & .489 & .234 & -1.55 & .38 \\
\hline Schizophrenia & $\begin{array}{c}\text { Alcohol } \\
\text { dependence }\end{array}$ & $-1.433^{*}$ & .489 & $.004^{*}$ & -2.40 & -.47 \\
\hline $\begin{array}{c}\text { Alcohol } \\
\text { dependence }\end{array}$ & $\begin{array}{c}\text { BPAD } \\
\text { Schizophrenia }\end{array}$ & $\begin{array}{c}.850 \\
1.433^{*}\end{array}$ & $\begin{array}{l}.489 \\
.489\end{array}$ & $\begin{array}{l}.084 \\
.004^{*}\end{array}$ & $\begin{array}{l}-.11 \\
.47\end{array}$ & $\begin{array}{l}1.81 \\
2.40\end{array}$ \\
\hline
\end{tabular}

The mean difference is significant at the 0.05 level. Scores of GHQ-12 are in schizophrenia 18 (1.95), bipolar group 18.58 (3.36) and alcohol dependence group 19.43 (3.36). On analysis of variance, $F$ value is 4.354 , which are statistically significant across groups. On post hoc analysis, the mean difference between schizophrenia and alcohol dependence group is statistically significant. Thus, means of GHQ-12 in alcohol dependence group is higher than Schizophrenia and Bipolar disorder group.

\begin{tabular}{|c|c|c|c|c|c|c|}
\hline \multirow{2}{*}{ 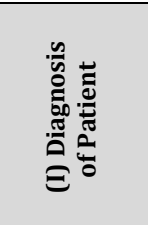 } & \multirow{2}{*}{ 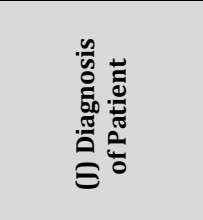 } & \multirow{2}{*}{ 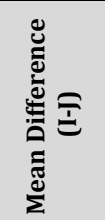 } & \multirow{2}{*}{ 章 } & \multirow[b]{2}{*}{ in } & \multicolumn{2}{|c|}{$\begin{array}{c}95 \% \\
\text { Confidence } \\
\text { Interval }\end{array}$} \\
\hline & & & & & 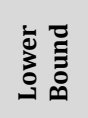 & ప̄ \\
\hline BPAD & $\begin{array}{c}\text { Schizophrenia } \\
\text { Alcohol dependence }\end{array}$ & $\begin{array}{c}1.73333 \\
-2.21667^{*}\end{array}$ & $\begin{array}{l}1.03911 \\
1.03911\end{array}$ & $\begin{array}{l}.097 \\
.034\end{array}$ & $\begin{array}{c}-.3173 \\
-4.2673\end{array}$ & $\begin{array}{l}3.7840 \\
-.1660\end{array}$ \\
\hline Schizophrenia & $\begin{array}{c}\text { BPAD } \\
\text { Alcohol dependence }\end{array}$ & $\begin{array}{l}-1.73333 \\
-3.95000^{*}\end{array}$ & $\begin{array}{l}1.03911 \\
1.03911\end{array}$ & $\begin{array}{l}.097 \\
.000\end{array}$ & $\begin{array}{l}-3.7840 \\
-6.0006\end{array}$ & $\begin{array}{c}.3173 \\
-1.8994\end{array}$ \\
\hline $\begin{array}{c}\text { Alcohol } \\
\text { dependence }\end{array}$ & $\begin{array}{c}\text { BPAD } \\
\text { Schizophrenia }\end{array}$ & $\begin{array}{l}2.21667^{*} \\
3.95000^{*}\end{array}$ & $\begin{array}{l}1.03911 \\
1.03911 \\
\end{array}$ & $\begin{array}{l}.034 \\
.000\end{array}$ & $\begin{array}{l}.1660 \\
1.8994\end{array}$ & $\begin{array}{l}4.2673 \\
6.0006 \\
\end{array}$ \\
\hline \multicolumn{7}{|c|}{ Table 3. Burden Assessment Schedule } \\
\hline
\end{tabular}

Table 3 shows the mean score and standard deviation of BAS between three groups. In schizophrenia group it is 79.68 (5.41), bipolar disorder group is 81.4 (4.41) and alcohol dependence group is 83.6 (6.35).

The $F$ value is 7.261 and $p$ value is 0.001 , which is statistically significant. On post hoc analysis, the mean difference between alcohol dependence group and other two groups is statistically significant. Thus, the means of BAS is high in alcohol dependence group than Schizophrenia and Bipolar disorder group.

\begin{tabular}{|ccccccc|}
\hline $\begin{array}{c}\text { (I) } \\
\text { Diagnosis } \\
\text { of Patient }\end{array}$ & $\begin{array}{c}\text { (J) } \\
\text { Diagnosis } \\
\text { of Patient }\end{array}$ & $\begin{array}{c}\text { Mean } \\
\text { Difference } \\
\text { (I-J) }\end{array}$ & $\begin{array}{c}\text { Std. } \\
\text { Error }\end{array}$ & Sig. & \multicolumn{3}{c|}{$\begin{array}{c}\text { 95\% Confidence } \\
\text { Interval } \\
\text { Lower }\end{array}$} & $\begin{array}{c}\text { Upper } \\
\text { Bound }\end{array}$ & Bound \\
BPAD & $\begin{array}{c}\text { Schizophrenia } \\
\text { Alcohol }\end{array}$ & -4.20000 & 6.70417 & .532 & -17.4304 & 9.0304 \\
& $\begin{array}{c}\text { dependence } \\
\text { BPAD }\end{array}$ & 4.60000 & 6.70417 & .494 & -8.6304 & 17.8304 \\
Schizophrenia & $\begin{array}{c}\text { Alcohol } \\
\text { dependence }\end{array}$ & 8.20000 & 6.70417 & .532 & -9.0304 & 17.4304 \\
Alcohol & BPAD & -4.60000 & 6.70417 & .191 & -4.4304 & 22.0304 \\
dependence & Schizophrenia & -8.80000 & 6.70417 & .494 & -17.8304 & 8.6304 \\
\hline \multicolumn{4}{c}{ Table 4. Global Assessment of Functioning } \\
\hline
\end{tabular}

Table 4 shows no statistical significance between means of GAF of three groups. The mean of schizophrenia is 64.08 (61.5); bipolar disorder group is 59.88 (10.01) and 55.28 
(12.3) in alcohol dependence group. The F value is 0.862 and $\mathrm{p}$ value is 0.424 which is not statistically significant similar to the finding on post hoc analysis.

\begin{tabular}{|c|c|c|c|c|c|}
\hline Variable & $\begin{array}{c}\text { Schizophrenia } \\
\text { Mean } \\
\text { (SD) }\end{array}$ & $\begin{array}{c}\text { Bipolar } \\
\text { Disorder } \\
\text { Mean (SD) }\end{array}$ & $\begin{array}{c}\text { Alcohol } \\
\text { Dependence } \\
\text { Mean (SD) }\end{array}$ & $\begin{array}{l}\text { One-way } \\
\text { ANOVA } \\
\text { F-value }\end{array}$ & p-value \\
\hline $\begin{array}{c}\text { CCL-problem } \\
\text { focused }\end{array}$ & $1.41(.61)$ & $1.4(.64)$ & $1.38(.62)$ & .294 & .764 \\
\hline $\begin{array}{l}\text { CCL-positive } \\
\text { distraction }\end{array}$ & $1.01(.59)$ & $.95(.62)$ & $.833(.64)$ & 1.34 & .264 \\
\hline $\begin{array}{c}\text { CCL- } \\
\text { acceptance }\end{array}$ & $1.85(.77)$ & $1.88(.76)$ & $1.78(.73)$ & .27 & .764 \\
\hline CCL-religion & $2.20(.97)$ & $2.35(.89)$ & $2.11(1.07)$ & .866 & .422 \\
\hline CCL-denial & $1.0(.58)$ & $.967(.609)$ & $1.05(.565)$ & .307 & .736 \\
\hline $\begin{array}{l}\text { CCL-social } \\
\text { support }\end{array}$ & $1.88(.99)$ & $1.55(.99)$ & $1.66(.96)$ & .176 & .175 \\
\hline Tabl & 5 Comnoric & Coping $C$ & $\begin{array}{l}\text { vles across } \\
\text { ck List }\end{array}$ & Grou & Ising \\
\hline
\end{tabular}

Table 5 shows the means and standard deviation of CCL sub scales between three groups. The mean in schizophrenia is 1.41 (0.61), bipolar disorder group is 1.4 (0.64) and alcohol dependence group is $1.38(0.62)$ with $\mathrm{F}$ value 0.294 and $P$ value of 0.764 . There is no statistical difference between the groups.

\section{DISCUSSION}

Although available literature studied burden of care and coping styles in caregivers broadly, studies specifically on spouses are less in whom the impact and perception of illness is different when compared to other care givers of family. The present study aims to assess the burden and coping exclusively in spouses of patients with schizophrenia, bipolar disorder and alcohol dependence syndrome. The significant findings obtained in the three groups were discussed. In one study, no difference seen between amount of burden in male and female spouses of patients with Schizophrenia, ${ }^{24}$ which is similar to above study finding.

The mean scores of CCL- problem solving is statistically significant across the two groups like that of CCL-social support subscale. A study reported that male caregivers used more avoiding coping style and undertook activities to provide diversion. Female caregivers used a less active approach and sought less social support. ${ }^{25}$ This study shows a statistically significant difference in problem solving and social support subscales across the genders.

On post hoc analysis, the mean difference between alcohol dependence group and other two groups is statistically significant. thus, the means of bas is high in alcohol dependence group than schizophrenia and bipolar disorder group. Previous studies found no significant difference in burden between alcohol dependence group and BPAD group though means are high in Bipolar disorder group. In contrast, this study reveals that means of burden in alcohol dependence are higher than other two groups reaching statistical significance.

Some studies revealed that emotion-focused coping strategy is found in most of the Schizophrenic relatives. ${ }^{26} \mathrm{~A}$ study found that fatalism and problem-solving contributed
$26.4 \%$ and $27.4 \%$ of the coping effort of caregivers respectively, followed by passivity at $22.4 \%$, expressiveaction at $13 \%$ and escape-avoidance at $10.8 \%$ with inference that relatives use a broad range of coping styles. ${ }^{27}$ The present study also shows that multitude of coping styles being employed by spouses of mentally ill persons. A study reported no difference in coping between the caretakers of Schizophrenia and Bipolar disorder. ${ }^{8}$ in the present study also, no statistically significant difference was found between coping styles in spouses of patients with schizophrenia, bipolar disorder and alcohol dependence.

In the present study we could not find any statistically significant difference in coping styles across the groups. It was found that the common coping style in spouses with mental illness is negative distraction ${ }^{12,13}$ but in the present study no particular coping style is commonly seen in spouses of mentally ill persons.

\section{Limitations}

The current study was conducted at a tertiary care center that may not represent the general population and study sample was mostly from the lower socioeconomic group. So the results cannot be extrapolated for middle and higher economic groups. Other factors that influence experience and reporting of burden like social support and expressed emotions were not taken into account.

\section{CONCLUSIONS}

Burden perceived by spouses of schizophrenia, bipolar disorder and alcohol dependence patients is significant and almost similar. Coping styles used by spouses are many with no particular predominant style. Measures to improve the treatment effectiveness may lead to reduction of perceived burden in the spouses. Psycho-education, family and couple therapy may help in better coping by spouses of mentally ill persons. Group therapy can help spouses in sharing their views and understanding various coping methods employed by others. Reducing burden on caregivers and enhancing their awareness of illness could lead to adoption of more adaptive coping styles by them.

There is a need for family intervention programs focusing on imparting psychoeducation to family members and imparting skills to manage spouses. Self-help groups for spouses should be encouraged where they can seek mutual support, learn from other's experiences and share problems with others for better coping. Periodic screening of spouses is required given their vulnerability to develop psychological problems along with financial incentives from the government agencies.

\section{ACKNOWLEDGEMENT}

Author would like to thank Dr. P.C.B. Gupta, Associate Professor, IMH, Hyderabad, for his guidance \& Dr. Siva Kumar, Associate professor, Govt. Medical College, Siddipet, Telangana for his constant support. 


\section{REFERENCES}

[1] Yip KS. Have psychiatric services in Hong Kong been impacted by the deinstitutionalization and community care movements. Administration and Policy of Mental Health 2000;27 (6):443-9.

[2] Avasthi A. Preserve and strengthen family to promote mental health. Indian J Psychiatry 2010;52 (2):113-26.

[3] Chan SWC, Yip B, Tso S, et al. Evaluation of a psycho education program for Chinese clients with schizophrenia and their family caregivers. Patient Education and Counselling 2009;75 (1):67-76.

[4] Chien WT, Chan SWC. One-year follow-up of a multiplefamily-group intervention for Chinese families of patients with schizophrenia. Psychiatric Services 2004;55 (11):1276-84.

[5] Chang KH, Horrocks S. Lived experience of family caregivers of mentally ill relatives. Journal of Advanced Nursing 2006;53 (4):435-43.

[6] Gururaj GP, Math SB, Reddy JYC, et al. Family burden, quality of life and disability in obsessive compulsive disorder: an Indian perspective. J Postgrad Med 2008;54 (2):91-7.

[7] Chadda RK, Singh TB, Ganguly KK. Caregiver burden and coping: a prospective study of relationship between burden and coping in caregivers of patients with schizophrenia and bipolar affective disorder. Social Psychiatry and Psychiatric Epidemiolog 2007;42 (11):923-30.

[8] Nehra R, Chakrabarti S, Kulhara P, et al. Caregivercoping in bipolar disorder and schizophrenia--a reexamination. Social Psychiatry and Psychiatric Epidemiology 2005;40 (4):329-36.

[9] Reinares M, Vieta E, Colom F, Martinez-Aran A, Torrent C, Comes M, Goikolea JM, Bemabaree A,Daban C, Sanchez-Moreno J. What really matters to bipolar caregivers-sources of family burden? J Affect Discord 2006 Aug;94 (1-3):157-63.

[10] Magliano L, Fadden G, Fiorillo A, et al. Family burden and coping strategies in schizophrenia: Are key relatives really different to other relatives? Acta Psychiatr Scand 1999;99 (1):10-15.

[11] Orford J, Templeton L, Velleman R, et al. Family members of relatives with alcohol, drug and gambling problems: a set of standardized questionnaires for assessing stress, coping and strain. Addiction 2005;100 (11):1611-24

[12] Rammohan A, Rao K, Subbakrishna DK. Burden and coping in caregivers of persons with schizophrenia. Indian J Psychiatry 2002;44 (3):220-7.

[13] Rammohan A, Rao K, Subbakrishna DK. Religious coping and psychological wellbeing in carers of relatives with schizophrenia. Acta Psychiatr Scand 2002;105 (5):35662 .
[14] Awad AG, Vorungati LNP. The burden of schizophrenia on caregivers: a review. Pharmaeconomics 2008;26 (2):149-62.

[15] Maji KR, Sood M, Sagar R, et al. A follow-up study of family burden in patients with bipolar affective disorder. Int J Soc Psychiatry 2012;58 (2):217-23.

[16] Perlick DA, Rosenheck RA, Miklowitz DJ, et al. Prevalence and correlates of burden among caregivers of patients with bipolar disorder enrolled in the Systematic Treatment Enhancement Program for Bipolar Disorder. Bipolar Disord 2007;9 (3):262-73.

[17] Perlick DA, Rosenheck RA, Clarkin JF, et al. Impact of family burden and affective response on clinical outcome among patients with bipolar disorder. Psychiatr Serv 2004;55 (9):1029-35.

[18] Mattoo SK, Nebhinani N, Kumar ABN, et al. Family burden with substance dependence: a study from India. Indian J Med Res 2013;137 (4):704-11.

[19] Tempier R, Boyer R, Lambert J, et al. Psychological distress among female spouses of male at-risk drinkers. Alcohol 2006;40 (1):41-9.

[20] Chakrabarti S, Gill S, Coping and its correlates among caregivers of patients with bipolar disorder: a preliminary study. Bipolar Disorders 2002;4 (1):50-60.

[21] Grover S, Chakrabarti S, Aggarwal M, et al. Comparative study of the experience of caregiving in bipolar affective disorder and Schizophrenia. Int J Soc Psychiatry 2012;58 (6):614-22.

[22] Thara R, Padmavathi R, Kumar S, et al. Burden assessment schedule: instrument to assess burden on caregivers of chronic mentally ill. Indian J Psychiatry 1998;40 (1):21-9.

[23] Rao K, Subbakrishna DK, Prabhu GG. Development of coping checklist- a preliminary report. Indian Journal of Psychiatry 1989;31 (2):128-33.

[24] Kumari S, Singh AR, Verma AN, et al. Subjective burden on spouses of Schizophrenia patients. Indian J Psychiatry 2009;18 (2):97-100.

[25] Goossens PJ, Van Wijngaarden B, Knoppert EAM, et al. Family care giving in bipolar disorder: caregiver consequences, caregiver coping styles, and caregiver distress. Int J Soc Psychiatry 2008;54 (4):303-16.

[26] Chandrasekaran R, Sivaprakash B, Jayestri SR. Coping strategies of the relatives of Schizophrenia. Indian J Psychiatry 2002;44 (1):9-13.

[27] Creado DA, Parkar SR, Kamath RM. A comparison of the level of functioning in chronic schizophrenia with coping and burden in caregivers. Indian J Psychiatry 2006;48 (1):27-33. 